\section{MRS Medals to Cross and Pennycook}

The MRS Medal Award was established to recognize a distinguished recent innovative achievement or discovery which is expected to have a major impact on the progress of any materials-related field. For 1992, two MRS Medal awards have been announced. They go to

L. Eric Cross, professor of electrical engineering, Pennsylvania State University, "in recognition of his leadership and vision in the atomic scale engineering of relaxor ferroelectric materials as the prototype of selfassembling nanocomposites," and

Stephen J. Pennycook, Oak Ridge National Laboratory, "for the development and application of incoherent (Z-contast) imaging in the scanning transmission electron microscope for direct determination of the atomic scale structure and chemistry of materials and interfaces."

Cross pioneered the development of the composite $\mathrm{PZT}+$ polymer transducer, which for the first time enhanced the figure of merit of an electroceramic product by more than three orders of magnitude. Subsequently, he and his group established the physics and mathematics for the tailor-making of a whole suite of highperformance electroceramic composite devices.

Much of the basic physics and the derived engineering of the relaxor family of composites based on lead magnesium niobate were developed by Cross. This work has already had a substantial impact in fields as diverse as medical diagnostic transducers, piezo motors, actuators, micro- and nano-displacement research devices, deformable mirrors, ink jet printing, infrared imaging systems, and smart sensors. Cross and his colleagues have been key innovators in opening up the whole rapidly advancing field of smart materials.

Cross received his $\mathrm{BSc}$ and $\mathrm{PhD}$ degrees from Leeds University. He continued his research at Leeds for several years before joining Pennsylvania State University in 1961. He now serves as Evan Pugh Professor of Electrical Engineering and has served as director of the Materials Research Laboratory at that university. Cross is a Fellow of the American Physical Society, the American Ceramic Society, IEEE, and the American Optical Society. He was elected to the National Academy of Engineering in 1983.

Pennycook, through the development of high-resolution incoherent (Z-contrast) imaging in the STEM, achieved a major long-term goal of electron microscopy: atomic resolution in a chemically sensitive
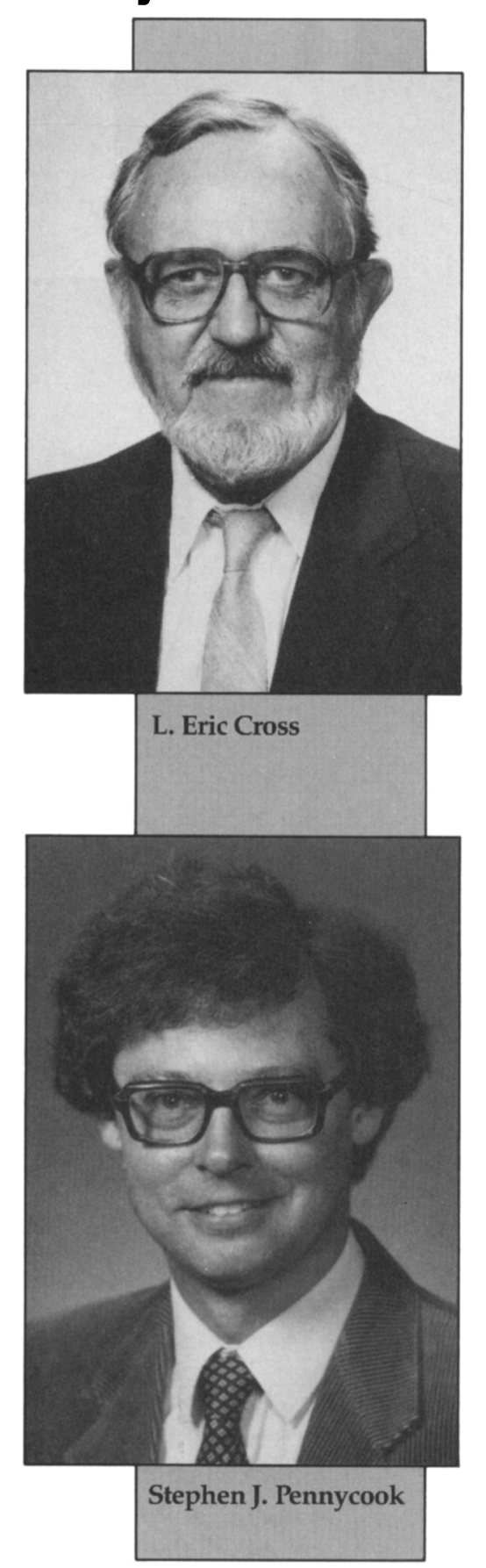

image which is directly and easily interpretable. This, in turn, constitutes a major advance for virtually every branch of materials research, where new opportunities are opened by the ability to directly associate chemical and microstructural information. The technique has already made big contributions in the areas of superconductors, semiconductors, ceramics, grain

\section{"ULTRA THIN"}

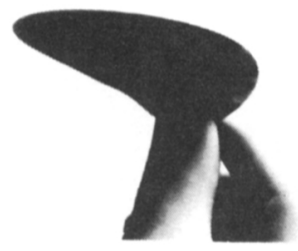

$2-4 \mu$ THIN

silicon membranes!

\section{Available in 2 and $3^{\prime \prime}$}

diameters, these double side polished elastic membranes combine a balance of thinness, parallelism and flatness heretofore not available in single crystal silicon.

\section{Applications include: \\ -micromachining \\ -X-ray lithography \\ -particle beam focusing \\ -stress diaphragms \\ -bonded silicon}

\section{All processing from crystal growth to polishing, is done on VSI premises.}

\section{Whether your requirements} are in research or production quantities, let's talk about putting these membranes to work for you.

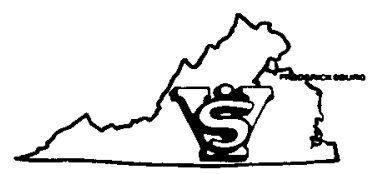

VIRGINIA SEMICONDUCTOR, INC.

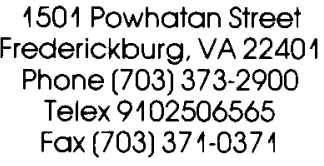

Circle No. 47 on Reader Service Card. 


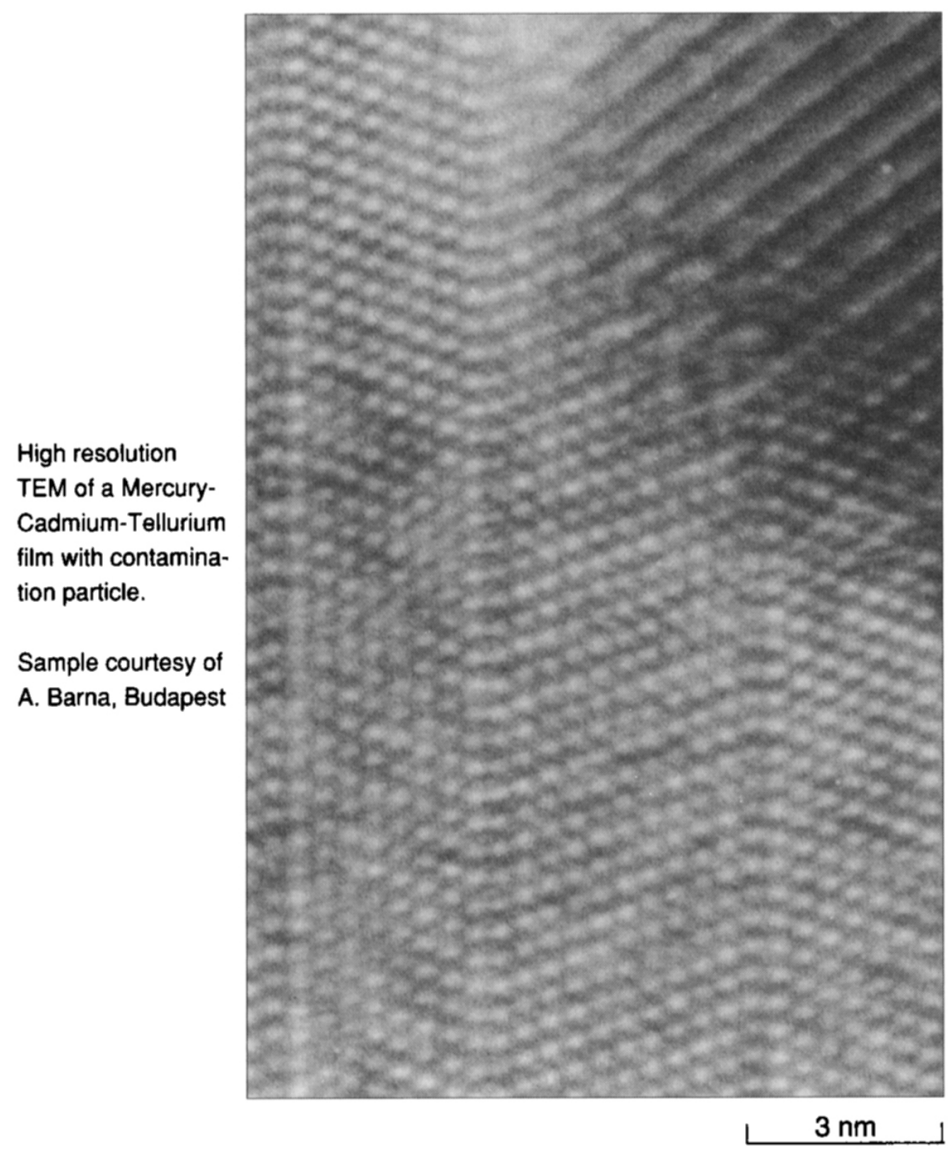

High performance lon Beam Thinning of solid state materials for SEM and TEM, specially suitable for thinning of inhomogeneous materials like minerals, ceramics, alloys, semiconductors, layer structures, etc.

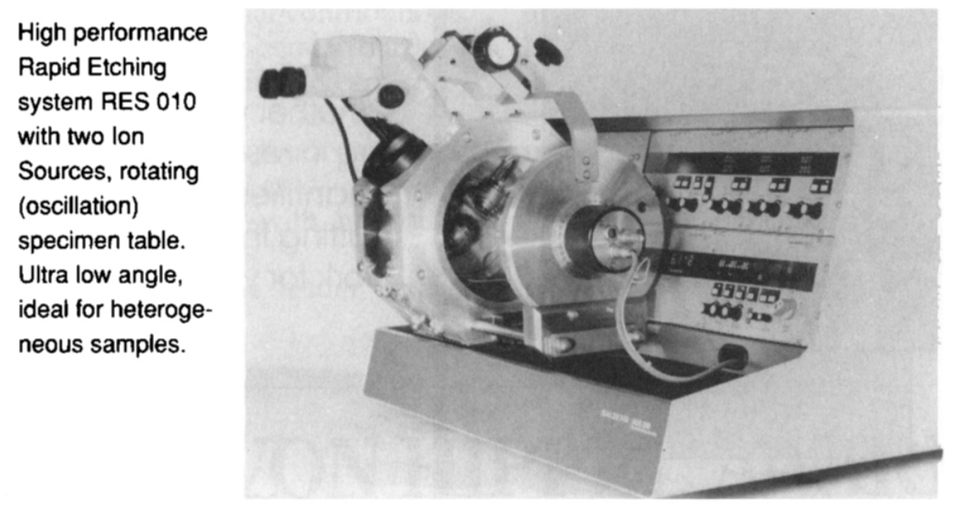

3NLTEC BAL-TEC PRODUCTS INC.

Your Partners in Preparation

984 Southford Road

P.O. Box 1221

Middlebury, CT 06762

Phone (203) 598-3660

(800) 875-3713

Fax (203) 598-3658 structure in metals and alloys, interfaces and catalysts. One example is Pennycook's recent imaging of striking local differences in the atomic structure of 1-2-3 superconductors when Er is substituted for $Y$.

Pennycook's approach departs from conventional phase-contrast highresolution electron microscopy. The technique relies on the detection of transmitted electrons scattered through high angles. The incoherent scattering of these electrons occurs mainly at unscreened nuclei, and thus gives an image with strong atomic-number (Z) contrast, and with only minor dependence on specimen thickness and microscope defocus. Recently, the NSF-ARM Panel proposed a major commitment of support for field-emission STEM instruments, a further recognition of the anticipated impact of Pennycook's work on the field.

Pennycook is a senior research scientist in the Solid State Division of Oak Ridge National Laboratory and leader of the Electron Microscopy Group. He received his $B A, M A$, and PhD degrees from the University of Cambridge, and came to Oak Ridge in 1982. In 1989, he received the Department of Energy award for outstanding scientific accomplishment and, in 1990, an R\&D-100 award for the development of Zcontrast STEM. He is Meeting Chair for the 1992 Fall MRS Meeting, and served as Guest Editor of the March, 1991 MRS Bulletin.

A wide variety of materials topics were represented among the 1992 Medal nominations, and the judging committee had a very challenging task in making a selection. Competition was intense, and the quality of nominations was very high. "The MRS Medal has clearly earned a position of prestige and stature," said Murray Gibson, awards committee chair. "Such a position can only be enhanced by the two new Medal winners, Professor Cross and Dr. Pennycook, whose accomplishments are held in such high regard in the professional community. We consider it our privilege to honor their achievements with the MRS Medal."

The MRS Medals will be awarded during the 1992 Fall Meeting Awards Ceremony on Thursday, December 3, in Salon $\mathrm{E}$ of the Boston Marriott. On Friday, December 4, the MRS Medal recipients will present special invited talks in Salon C/D. At 12:05 p.m., Cross will speak on "Relaxor Ferroelectrics: Self-Assembling Nanocomposites," followed by Pennycook's presentation at 12:45 p.m. on "Direct Atomic Imaging of Materials by Zcontrast STEM." 